\title{
STUDY OF PROPORTIONAL AND ABSOLUTE VOLUME OF PLACENTAL PARENCHYMA AND NON- PARENCHYMA BETWEEN NORMAL PREGNANT AND PREECLAMPTIC WOMEN
}

\author{
KISHWARA $\mathrm{S}^{1}$, NURUNNABI ASM ${ }^{2}$, BEGUM M ${ }^{3}$, AHMED R ${ }^{4}$, ARA $^{5}$
}

\begin{abstract}
:
Context: The changes in volume of the placenta and its internal components are evident in different maternal diseases like preeclampsia. Postnatal examination of the placenta is an important method for assessing maternal and fetal condition in antenatal and perinatal periods and enriching practical knowledge.

Study design: Cross-sectional descriptive type.

Place and period of study: Department of Anatomy, Dhaka Medical College, Dhaka from August 2005 to June 2006.

Materials \& Methods: 54 human placentae from Bangladeshi women were collected from the Department of Obstetrics \& Gynaecology of Dhaka Medical College Hospital and Sir Salimullah Medical College Hospital, of which 27 from normal uncomplicated pregnancies (control group) and another 27 from pregnancies complicated by preeclampsia (study group) where the patients were normotensive previously.

Results: Both the proportional and absolute volume of placental parenchyma were found lower in preeclamptic women than those of normal pregnant women $(P<0.001)$. But only in the absolute volume of non-parenchyma of the placenta, there was difference in between two groups $(P<0.001)$, no difference found in relative volume $(P>0.50)$.
\end{abstract}

Key words: placenta, volume, parenchyma, non-parenchyma, preeclampsia.

J Dhaka Med Coll. 2008; 17(2) : 78-82.

\section{Introduction:}

The placenta is essential for the survival of the fetus. It undergoes different changes in weight, volume, structure, shape and function continuously throughout the gestation to support the prenatal life ${ }^{1}$. The architecture of the placenta is found to be changed in many maternal diseases like diabetes mellitus, hypertension, preeclampsia, eclampsia etc. Among those, gestational diabetes and preeclampsia are two pregnancy-induced metabolic diseases that may jeopardize the health of the mother and the fetus ${ }^{2}$. It is a remarkable matter that the placenta has got both anatomical and functional components from both the maternal and the fetal sources and shows tremendous functional interdependence between those two components. Any anatomical variation or pathophysiological change in the maternal part may influence the fetal part and thereby may complicate the fetal well-being. Therefore, postnatal examination of the placenta can be an important method for assessing maternal and fetal condition in antenatal and perinatal periods ${ }^{3}$.

The changes in volume of the placenta and its internal components are evident in preeclampsia and eclampsia and the uteroplacental ischaemia is held responsible

1. Assistant Professor, Department of Anatomy, Dhaka Medical College, Dhaka.

2. M.Phil. Student, Department of Anatomy, Dhaka Medical College, Dhaka.

3. Associate Professor, Department of Anatomy, Dhaka Medical College, Dhaka.

4. Lecturer, Department of Anatomy, Dhaka Medical College, Dhaka.

5. Professor and Head, Department of Anatomy, Dhaka Medical College, Dhaka.

Correspondence: Dr. Segupta Kishwara. 
for most of the placental changes ${ }^{4}$. Along with other morphological changes, marked changes are found in parenchymal and nonparenchymal structures of the placenta leading to change in its volume. The definitive pathogenesis of these structural abnormalities, their correlation with placental function and their relationship to perinatal morbidity and mortality in these high-risk pregnancies are still to explore ${ }^{5}$. The aim of the present study is to see the range of alteration in parenchyma of the placentae of preeclamptic mothers in comparison to normal pregnancies. The findings are expected to increase the information pool, and thereby, help the clinicians to adopt appropriate plan of treatment in preeclampsia and eclampsia, especially in the developing countries like Bangladesh, where the vulnerability is very high.

\section{Materials and Methods:}

\section{Materials:}

A cross-sectional descriptive study was carried out in the Department of Anatomy, Dhaka Medical College, Dhaka from August 2005 to June 2006 on 54 human placentae from Bangladeshi women, of which 27 collected from normal uncomplicated pregnancies (considered as control group) and another 27 from pregnancies complicated by preeclampsia (considered as study group) where the patients were normotensive previously. The placentae were collected from pregnant women whose deliveries (either normal vaginal delivery or Caesarean section) were conducted in the Department of Obstetrics \& Gynaecology, Dhaka Medical College Hospital and Sir Salimullah Medical College Hospital. Pregnant women were selected between 35-40 weeks of gestation. Selection of the control and the study group was done on the basis of diagnosis by a registered physician or from the hospital record. Each of the placentae was collected in a labeled plastic bag within 6 hours of delivery.

\section{Methods:}

Procedure of the study:

54 placentae were considered for estimation of the volume of parenchyma and nonparenchyma. The percentage of the total volume occupied by parenchyma and nonparenchyma was calculated by using the macroscopic point-counting techniques described by Aherne and Dunnill (1966) ${ }^{6}$. Parenchyma consists of villi, their fetal vessels and maternal intervillous space and nonparenchyma consists of chorionic and decidual plates, fetal vessels of diameter $>0.1$ $\mathrm{cm}$ and intercotyledonary septa along with the pathological components e.g. old and recent infarcts and subchorionic fibrin ${ }^{7}$. As the parenchyma is that part of the placenta which contains the structures or components that are strictly concerned with metabolic exchange between the mother and fetus, the pathological components were included in the nonparenchyma in the present study ${ }^{7}$.

Each placenta was placed flat on a flat tray on fetal surface and cut into 10 to 15 slices, each $1 \mathrm{~cm}$ in thickness with a sharp knife (Fig.1). Each slice had 4 surfaces i.e. one maternal, one fetal and two internal surfaces. The internal surface was carefully examined for any unusual thickness and change of colour. The placental tissue was observed for parenchyma and non-parenchyma (Fig.2). In this study, a grid composed of points spaced $0.5 \mathrm{~cm}$ apart drawn on transparent plastic material, was placed on the internal surface of each of the fixed slices of placenta. The position of each point, whether lying over parenchyma or nonparenchyma, was recorded (Fig.3). Thus, for each of the placentae, the positions of about 1000 points were recorded. Because of smaller size, some placentae could not accommodate 1000 points. From the 1000 points, the percentage of the points falling on the parenchyma and non-parenchyma were calculated. These percentages represented the proportional volume of individual components.

Absolute volume of the parenchyma and nonparenchyma were calculated from the total volume of the placenta measured by water displacement method $^{8}$.

\section{Statistical processing of data:}

The collected data were processed and statistical analyses were done by unpaired Student's 't' test. All the statistical analyses were done by using the SPSS 11.0 version. 


\section{Results:}

The mean \pm SD proportional volume of the parenchyma of the placenta was $76.72 \pm 4.09$ and $70.51 \pm 5.53$ percent in group $A$ (control) and group $B$ (preeclampsia) respectively. Statistically the difference between the two groups was significant at $\mathrm{P}<0.001$. The mean $\pm \mathrm{SD}$ absolute volume of the parenchyma of the placenta was $296.90 \pm 68.98$ and $206.28 \pm 53.62 \mathrm{ml}$ in group A and B respectively. Statistically the difference between the two groups was significant at $\mathrm{P}<0.001$ (TableI \& Fig.4).

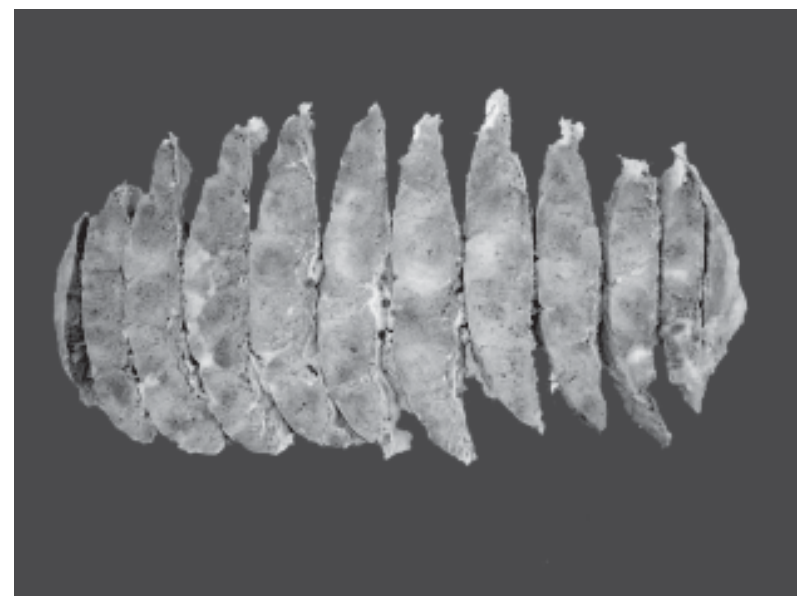

Fig. 1: Photograph of $1 \mathrm{~cm}$ thick slices of a placenta for macroscopic study. The internal surfaces of the placental slices are visible.

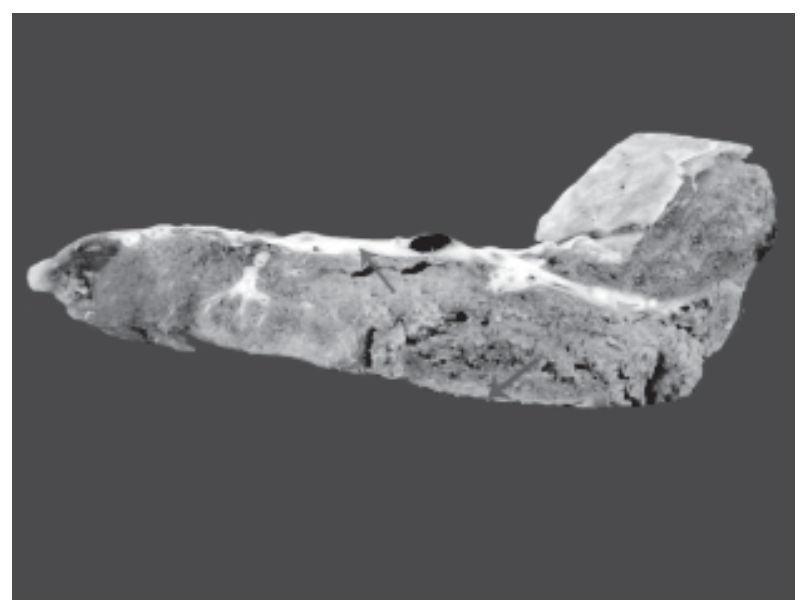

Fig. 2: Photograph of the internal surface of a slice of a placenta showing parenchymal and nonparenchymal components. The arrow heads indicate the non-parenchymal components (green arrow-placental septum; red arrow- decidual plate; pink arrow-chorionic plate). The rest constitutes the parenchyma.
The mean \pm SD proportional volume of the nonparenchyma of the placenta was $23.29 \pm 4.10$ and $29.49 \pm 5.53$ percent in group A and group B respectively. Statistically the difference between the two groups was significant at $\mathrm{P}<0.001$. The mean \pm SD absolute volume of the nonparenchyma of the placenta was $89.51 \pm 23.51$ and $86.83 \pm 28.16 \mathrm{ml}$ in group A and B respectively. There was no significant difference between the two groups (Table-I \& Fig.4).

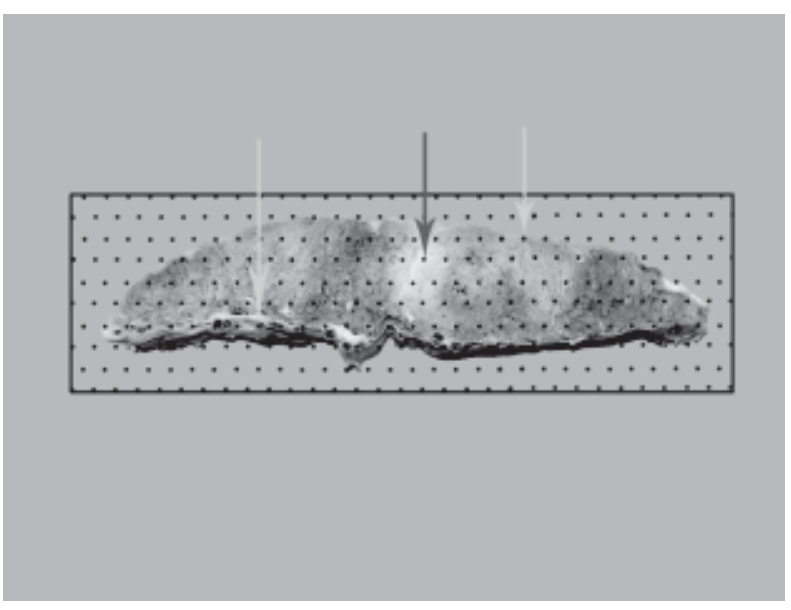

Fig. 3: Photograph of the cut surface of a slice of a placenta showing the procedure of point counting using the computer generated plastic grid placed on the cut surface of the slice. Red arrow indicates the point on the parenchyma, while yellow arrows indicate two points on non-parenchymal components.

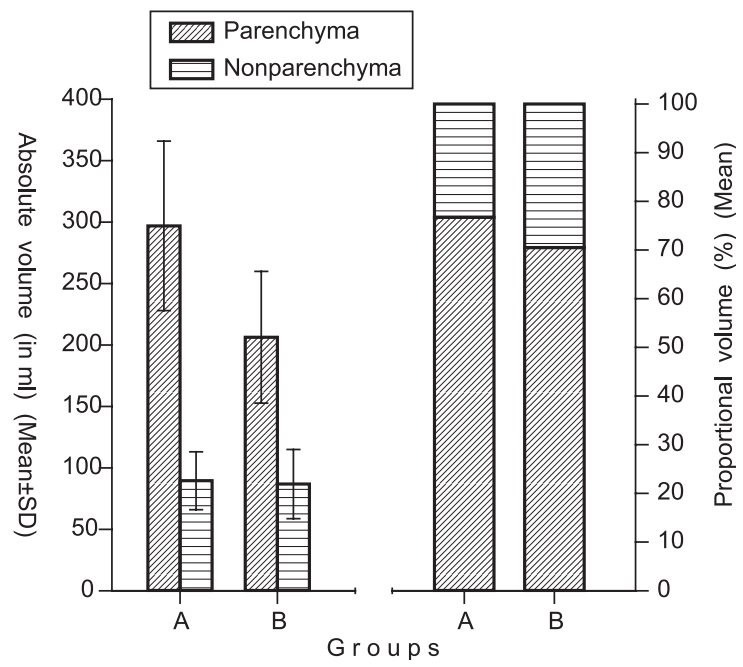

Fig. 4. Absolute and proportional volume of placental parenchyma and non-parenchyma in the two study groups (group A: Control, group B: Preeclampsia). 
Table-I

Comparison of proportional and absolute volume of placental parenchyma and non-parenchyma between the two study groups

\begin{tabular}{lccc}
\hline Variables & $\begin{array}{c}\text { Group A } \\
(\mathrm{n}=27) \\
\text { Mean } \pm \text { SD }\end{array}$ & $\begin{array}{c}\text { Group B } \\
(\mathrm{n}=27) \\
\text { Mean } \pm \mathrm{SD}\end{array}$ & P value \\
\hline Parenchyma & & & \\
Proportional & $76.72 \pm 4.09$ & $70.51 \pm 5.53$ & $<0.001^{* * *}$ \\
volume (\%) & $(67.20-82.40)$ & $(62.20-81.40)$ & $<0.001^{* * *}$ \\
Absolute & $296.90 \pm 68.98$ & $206.28 \pm 53.62$ & \\
volume (in ml) & $(186.20-470.92)$ & $(117.60-337.59)$ & \\
Non-parenchyma & & & \\
Proportional & $23.29 \pm 4.10$ & $29.49 \pm 5.53$ & $>0.001^{* * *}$ \\
volume (\%) & $(17.60-32.80)$ & $(18.60-37.80)$ & \\
Absolute & $89.51 \pm 23.51$ & $86.83 \pm 28.16$ & \\
volume (in ml) & $(47.90-139.08)$ & $(45.60-140.98)$ & \\
\hline
\end{tabular}

Group A: Control

Group B: Preeclampsia

Figures in parentheses indicate range. Statistical analysis done by unpaired Student's ' $\mathrm{t}$ ' test, ns = not significant, ${ }^{* * *}=$ significant.

\section{Discussion:}

Barua $(2002)^{9}$ stated that mean absolute volume of placenta was significantly lower in eclampsia group as compared to control group. She stated that the eclampsia group differed significantly from control group by having a larger value for the proportional volume of the non-parenchyma but smaller value for the others. Teasdale $(1987)^{10}$ found absolute volume of placenta was significantly decreased in preeclampsia group. There was a significant reduction of parenchymal tissue due to significant reduction in peripheral villous tissue mass, fetal capillary and intervillous space volume. There was a significant reduction in the volume of each of the components in placentae of the preeclamptic mother. All parenchymal tissue components i.e. IVS, peripheral villous, trophoblast and capillaries, were decreased by approximately $50 \%$ in the placenta of preeclamptic mother. $\mathrm{He}$ also found that there was significant less villous tissue in the placentae of the preeclamptic mothers compared with the controls. This marked difference in the villous tissue was strictly the result of a $52 \%$ reduction in the mass of peripheral villous tissue, whilst the stem villous tissue was shown to be increased in the placentae of the growth retarded infants. Intervillous space volume was significantly reduced in relation to the total villous tissue volume. This study had also shown that there was proportionally more stem and less peripheral villous tissues in the placentae of the preeclmptic compared to the controls. Boyd and Scott (1985) ${ }^{11}$ shows that the placentae from women suffering from preeclampsia and from those giving births to small-for-dates' (SFD) babies consistently have a smaller total volume and volume of parenchyma and more have areas of multiple infarctions when compared with placentae from uncomplicated pregnancies of comparable gestation. Conversely, those placentae from patients with hypertension uncomplicated by preeclampsia have a similar or higher volume of parenchyma. Aherne and Dunnill (1966) ${ }^{7}$ found that the volume proportion of chorionic tissue and of intervillous space in hypertensive pregnancies did not differ from the corresponding normal values, although there were differences in the absolute volume. They 
stated that for all types of placenta, the volume of the intervillous space is reduced slightly by the deposition of fibrin. The findings of the present study conform to the reports of Boyd and Scott $(1985)^{11}$ and Teasdale (1987) ${ }^{10}$, partially to Aherne and Dunnill (1966) ${ }^{7}$. But, Teasdale $(1985)^{2}$ did not find any significant difference in absolute volume, in the proportions of parenchymal and nonparenchymal tissues and in the distribution of the parenchymal tissue components between the placentae of the preeclamptic mothers and the control. Possible explanation behind is that the degree of severity or the duration of the disease process was not enough to produce significant morphologic changes.

Jones and Fox (1980) ${ }^{12}$ suggested that some of the morphological changes in preeclampsia could represent the compensatory mechanism in the placenta e.g. an increase in stem villous volume, marked reduction of total villous volume and intervillous space volume etc. that are helpful to some extent to overcome the unfavourable maternal environment, in spite of the reduction in volume (both proportional and absolute). But Teasdale (1987)10 demonstrated that the placenta of preeclamptic mother with marked intrauterine growth retardation as in the present study can suffer significant morphological alteration which could not be prevented by potential repair mechanism. There is an abnormal pattern of maturation or arborization of the villous tree, characterized by significant decrease in the peripheral villous tissue and relative increase in stem villi.

\section{Conclusion:}

It is seen in the present study that proportional and absolute volume of parenchyma of preeclamptic placenta are reduced significantly. Proportional volume of nonparenchyma is also reduced significantly in the preeclampsia group. This morphological alteration in placenta due to preeclampsia contributes to the high mortality and morbidity of both mothers and neonates in our country. So, proper antenatal care must be given to all pregnant women to screen for preeclampsia and take proper measures to control this deadly condition. Moreover, there is a need for more biochemical and physiological investigations as well as further cytomorphometric placental studies in order to determine more precisely the role of placenta in the pathogenesis of preeclampsia.

\section{References:}

1. Teasdale F. Gestational changes in the functional structure of the human placenta in relation to fetal growth: a morphometric study. Am J Obstet Gynecol. 1980; 137: 560-3.

2. Teasdale F. Histomorphometry of the human placenta in maternal preeclampsia. Am J Obstet Gynecol. 1985; 152: 25-31.

3. Kalra VB, Agarwal A, Sareen PM, Kalra R. Histopathological Changes in placenta in toxaemia of pregnancy. J Obs Gynae India. 1985; 35: 8690.

4. Fox H and Jones CJP. Pathology of trophoblast. In: Loke YW and White A. eds. Biology of trophoblast. $3^{\text {rd }}$ ed. New York: Elsevier; 1983. p.137-85.

5. Fox H. The placenta in maternal disorders. In: Bennington JL. ed. Pathology of the placenta. $2^{\text {nd }}$ ed. Philadelphia: W. B. Saunders; 1978. p.21337.

6. Aherne W, Dunnill MS. Quantitative aspects of placental structure. J Pathol Bacteriol. 1966; 91: 123-39.

7. Laga EM, Driscoll SG, Munro HN. Quantitative studies of human placenta. I.Morphometry. Biol Neonate. 1973; 23: 231-59.

8. Brown RA, Al-Moussa M, Beck JS. Histometry of normal thyroid in man. J Clin Pathol. 1986; 39: 475-82.

9. Barua R. Macroscopic and microscopic changes in human placenta in gestational diabetes and eclampsia [thesis]. Dhaka: BSMMU; 2002.

10. Teasdale F. Histomorphometry of the human placenta in preeclampsia, associated with severe intrauterine growth retardation. Placenta. 1987; 8: 119-28.

11. Boyd PA, Scott A. Quantitative structural studies on human placentas associated with preeclampsia, essential hypertension and intrauterine growth retardation. Br J Obstet Gynaecol. 1985; 92: 71421.

12. Jones CJP, Fox H. An ultrastructural and ultrahistochemical study of the human placenta in maternal preeclampsia. Placenta. 1980; 1: 6176. 